\title{
MIÍASE CUTÂNEA HUMANA COM ENVOLVIMENTO CAVITÁRIO ORBITAL: DESCRIÇÃO DE UM CASO CLÍNICO
}

\author{
HUMAN CUTANEOUS MYIASIS WITH ORBITAL CAVITY \\ INVOLVEMENT: A CASE REPORT
}

\author{
Jamil Elias Dib ${ }^{1}$, Matheus Branco Elias Dib ${ }^{2}$, Pablo Gimenes Tavares ${ }^{3}$, \\ Frab Norbeto Bóscolo ${ }^{4}$, Raphael Navarro Aquilino ${ }^{5}$ \\ 1 Universidade Regional de Gurupi - UNIRG, Departamento de Odontologia, Gurupi, TO e \\ coordenador do Serviço de Cirurgia Maxilo-Facial do Hospital de Urgências de \\ Anápolis, GO \\ 2 Universidade Santa Cecília - UNISANTA, Curso de Odontologia, Santos, SP \\ 3 Universidade Regional de Gurupi - UNIRG, Departamento de Odontologia, Gurupi, TO e \\ Universidade de Taubaté - UNITAU, Taubaté, SP \\ 4 Faculdade de Odontologia de Piracicaba - FOP/UNICAMP \\ 5 Autor para contato: Universidade Regional de Gurupi - UNIRG, Departamento de \\ Odontologia, Gurupi, TO e Doutorando em Radiologia Odontológica da Faculdade de \\ Odontologia de Piracicaba - FOP/UNICAMP; 63-3312-0175; \\ e-mail: raphaelnavarroaquilino@uol.com.br
}

Recebido para publicação em 31/08/2007

Aceito para publicação em 17/10/2007

\section{RESUMO}

As miíases cutâneas e cavitárias são patologias humanas freqüentemente causadas pela infestação de larvas de moscas da ordem díptena, principalmente as Cochliomyia homnivorax e Dermatóbia hominis. As mesmas parasitam o homem quando encontram condições favoráveis, tais como feridas expostas, higiene oral e corporal deficiente, paciente em situações especiais, como epilépticos, alcoólatras, idosos com saúde geral debilitada, deficientes mentais e trabalhadores rurais em contato constante e direto com animais domésticos. Recursos de imagens, como tomografia computadorizada e outros, são essenciais para a localização e delimitação do comprometimento de estruturas ósseas e tecidos moles na região da lesão. O tratamento requer a remoção mecânica das larvas e, na maioria das vezes, o uso de substâncias químicas curativas e profiláticas das infecções secundárias havendo, na maioria das vezes, um bom prognóstico mas podendo eventualmente haver seqüelas e deformidades.

Palavras-chave: miĺase, Dermatóbia hominis, miíase orofacial, ivermectina. 


\begin{abstract}
Cutaneous and cavity myiases are a human pathology frequently caused by infestation with dipterous fly maggots, mainly Cochliomyia homnivorax and Dermatobia hominis. These parasites infect human beings when they find a favorable condition, such as an exposed wound, deficient oral and body hygiene, patients in special conditions, for example, epileptics, alcoholics, elderly people with a debilitated health, mentally deficient people and agricultural workers in direct contact with domestic animals. Image resources, such as computerized tomography and others, are essential for the localization and delimitation of injuries caused to the osseous structures and soft tissues in the vicinity of the infected area. The treatment consists of the mechanic removal of the larvae and, in many cases, the topical application of prophylactic and curative drugs to prevent secondary infections. The prognostic is usually good, but sequels and deformities can occur.
\end{abstract}

Key words: myiases, Dermatobia hominis, orbital myiases, ivermectin

\section{Introdução}

A miíase é uma patologia parasitária comum em animais domésticos (BALIGA, DAVIS, RAJASEKHAR, 2001) sendo ocasionada através da infestação pelas larvas de moscas, principalmente as Cochliomyia homnivorax que obrigatoriamente parasitam os mamíferos, incluindo o homem. O termo miíase (grego myia,mosca e iasis, afecção, moléstia) inicialmente foi introduzido por F.W Hope(ÇAÇA et al., 2003) e se refere à invasão dos tecidos por ovos ou larvas de moscas da ordem Díptera. As larvas depositam seus ovos em tecidos doentes e necróticos, mas podem fazê-los em zonas do corpo aparentemente sãs. Trata-se de um tipo de patologia muito freqüente nos pacientes de regiões tropicais, que possuem nível sócio econômico baixo, de íntimo contato com animais, ou ainda naqueles com higiene corporal precária, alcoólatras, pacientes epilépticos e em deficientes mentais ou saúde geral debilitada (ÇAÇA et al., 2003; COUPPIÉ et al., 2005).

A miíase cutânea ou cavitária pode provocar destruição maciça dos tecidos cutâneos ou cavitários como as cavidades bucal, nasal, ocular ou sinusais e ainda estar acompanhada por intensas reações inflamatórias e infecciosas secundárias, sofrendo o paciente o risco de desenvolver uma bacteremia ou septicemia em virtude de uma infecção secundária (COUPPIÉ et al., 2005).

O diagnóstico, quando acomete a cavidade bucal consiste principalmente no seu aspecto clínico e alguns recursos imaginológicos como exames por tomografia computadorizada podem ou devem ser usados dependendo da gravidade do caso para verificar a extensão do compromotimento e relação do tecido ósseo com o tecido mole.

O tratamento basicamente consiste de forma mecânica, ou seja, na remoção das larvas uma por uma. Em casos onde as larvas se localizam mais profundamente nos tecidos, como na orelha média e cavidades nasais e sinusais, torna-se necessário o uso de medicamentos, como o óleo canforado, occiunureto de mercúrio, entre outros, para que as larvas migrem para a superfície facilitando sua remoção. O uso da ivermectina via oral ou tópica pode ser usado como tratamento medicamentoso para erradicação das larvas (COUPPIÉ et al., 2005).

O objetivo deste trabalho é ilustrar um caso clínico de um paciente acometido por miíase envolvendo cavidade orbitária descrevendo suas condições clínicas e achados radiográficos em imagens por tomografia computadorizada, bem como descrever o tratamento proposto e sua proservação. 


\section{Caso clínico}

Paciente M.C., 32 anos, sexo masculino, leucoderma, apresentando queixas de dor e tontura foi hospitalizado no hospital de Urgências de Goiânia estado de Goiás. Ao exame clínico foi observado um grande ferimento envolvendo quase totalidade da hemiface direita e região de órbita e apresentando uma grande quantidade de tecido necrótico, odor fétido e alguns pontos hemorrágicos com presença de pequenas larvas vivas em meio à lesão (figura 1). Durante a anamnese, o paciente não soube informar com exatidão sobre as causas do problema. O mesmo também se apresentava febril com um quadro moderado de desidratação e subnutrição onde suas condições clínicas gerais estavam debilitadas com alguns sinais e sintomas de toxemia como dispnéia, taquicardia, perda de apetite, sudorese e palidez cutânea. Os exames laboratoriais revelaram uma leucocitose e neutrofilia com curva de desvio à esquerda sugestivo de um padrão de bacteremia.

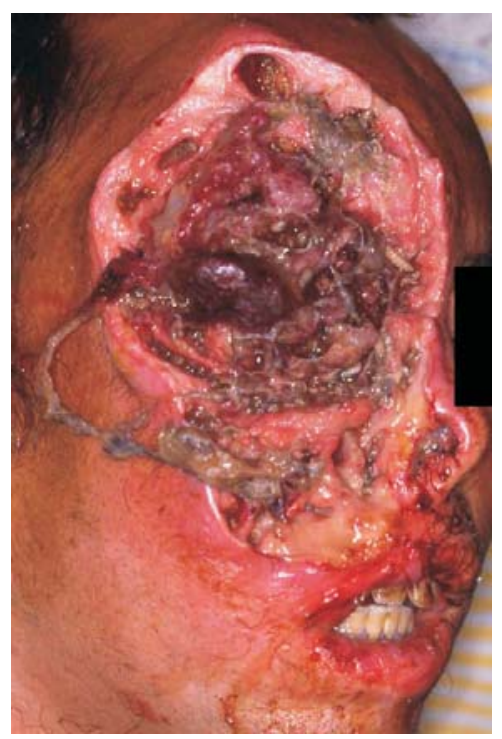

Figura 1 - Aspecto inicial do paciente ao chegar ao departamento de emergência. Note as larvas sobre a ferida e o aspecto de tecido necrótico ao redor.
A conduta imediata foi hidratar o paciente com solução glicofisiológica de $500 \mathrm{ml}$ de soro glicosado a $5 \%$ e $1200 \mathrm{ml}$ de solução de cloreto de sódio a $0,9 \%$. Foi administrado, além do soro, $2 \mathrm{ml}$ de dipirona e uma associação de gentamicina na concentração de $80 \mathrm{mg}$ por via endovenosa nos intervalos de 8 em 8 horas. Ceftriaxona na concentração de $2 \mathrm{~g}$ foi aplicado também por via endovenosa uma vez ao dia, e ainda a solução de metronidazol também por via endovenosa na concentração de 500 mg em intervalos de 6 em 6 horas. Esta conduta empírica deveu-se ao fato do quadro infeccioso e com o objetivo de atingir as bactérias gram positivas, gram negativas e também os anaeróbios, o que foi posteriormente confirmada através da cultura e antibiograma.

O paciente foi submetido a exames por imagens utilizando tomografia computadoriza da face (TC) em cortes axiais com matriz de 512x5212 pixels e janelas para tecido ósseo e tecido mole. Nas imagens observou-se total envolvimento da cavidade orbitária direita, com presença de uma massa homogênea semelhante à tecido mole na região de globo ocular e estruturas anexas (figuras 2A e 2B). A parede da fossa nasal direita estava preservada. No procedimento de emergência foi obtida uma radiografia PAde tórax onde as estruturas observadas encontravam-se dentro dos padrões de normalidade.

Concluído os exames imaginológicos, o paciente foi conduzido ao centro cirúrgico para o debridamento da ferida e remoção das larvas. O procedimento foi feito sob sedação e infiltração anestésica local com solução de cloridrato de lidocaína a 3\% com norepinefrina. As larvas foram removidas usando pinça clínica e manobra de dissecação com tesouras de Metzembaum e pinças hemostáticas (figura 3). Durante o ato cirúrgico, um fragmento de tecido foi retirado para realização de exame histopatológico para exclusão de qualquer neoplasia, o que confirmou apenas um estado de caráter inflamatório. 


\section{0}
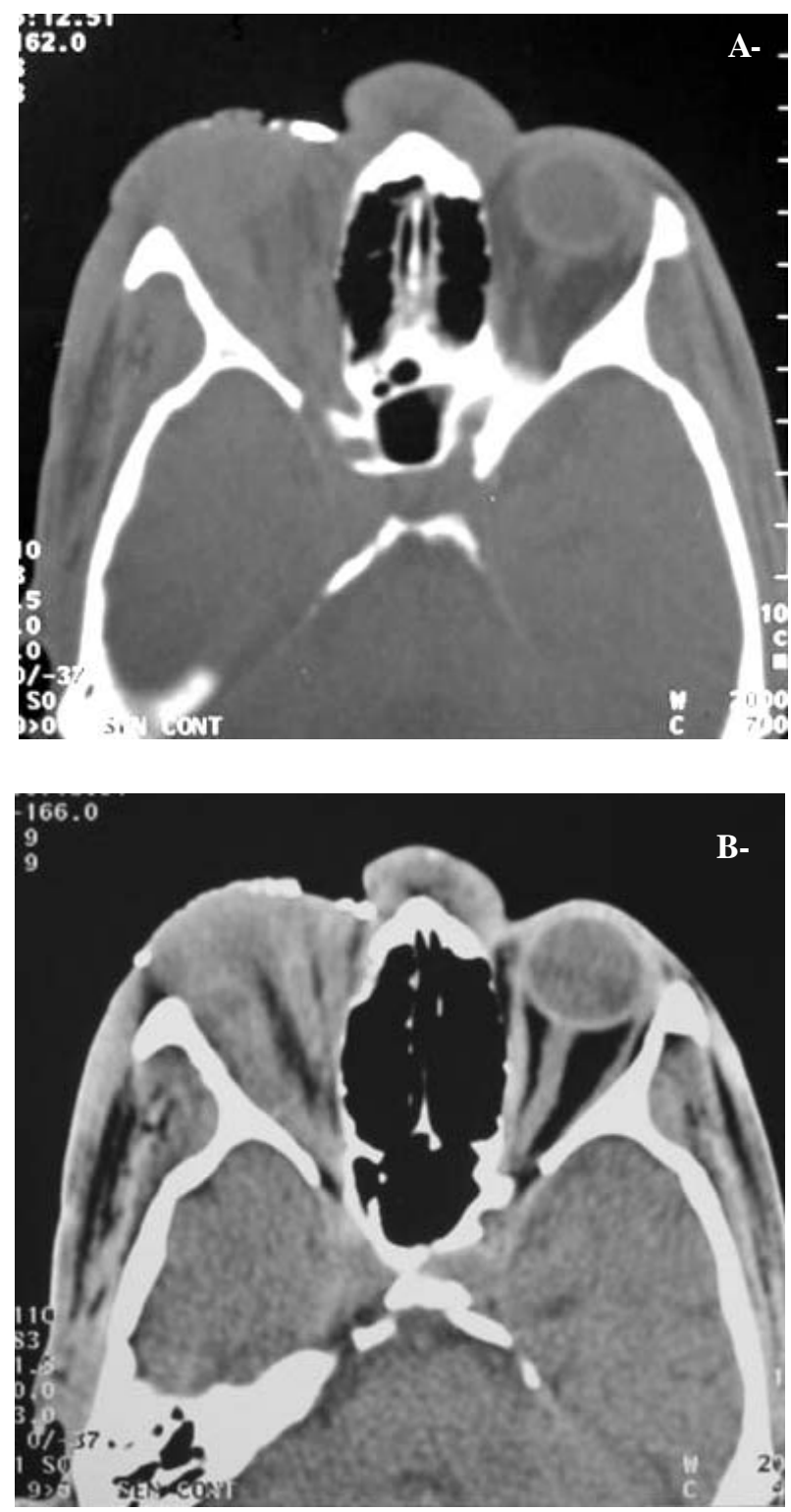

Figura 2 - A- Corte axial em TC. Note a presença de massa homogenia na região de globo ocular direito e a parede da fossa nasal preservada; B- janela para tecidos moles. Observe o total comprometimento cavidade orbitária direita.

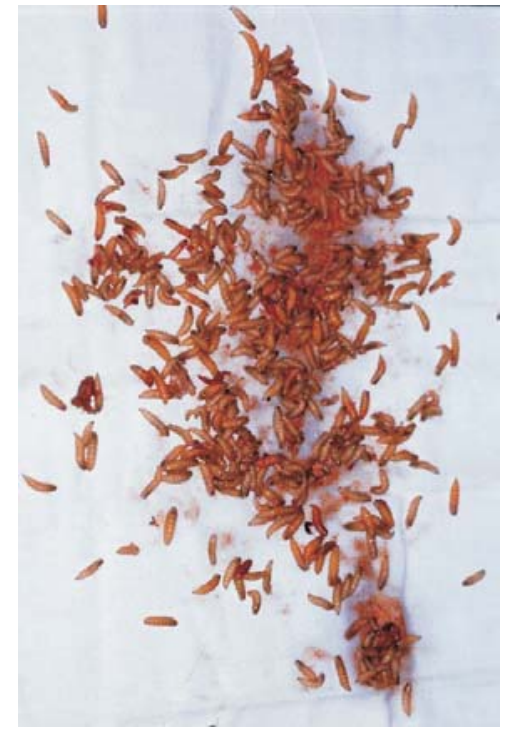

Figura 3 - Quantidade de larvas removidas da ferida.

Para a cicatrização e descontaminação total da ferida, colocou-se uma camada de iodofórmio e uma camada de açúcar cristalizado (figuras 4A e 4B). A partir do segundo dia pós-operatório foram realizados curativos diretos, lavando exaustivamente a ferida com solução fisiológica a 0,9 \% e mantiveram-se os curativos com iodofórmio e açúcar durante cinco dias juntamente com administração de $10 \mathrm{~g} / \mathrm{ml}$ de Ivermectina por via endovenosa em períodos de três vezes ao dia durante três dias. Foram removidas, neste intervalo, aproximadamente 33(trinta e três) larvas mortas. A partir do sexto dia os curativos foram substituídos pelo gel hidratante de alginato de cálcio e sódio e carboximetilcelulose (SAF- GEL -Bristol-Meyers-Squibb) devido o mesmo possui a capacidade de hidratar os tecidos e também auxiliar na remoção dos exudatos. O período de administração tópica do respectivo medicamento foi de vinte e um dias enquanto o paciente permaneceu hospitalizado. O tratamento com antibacterianos foi mantido por dez dias. 

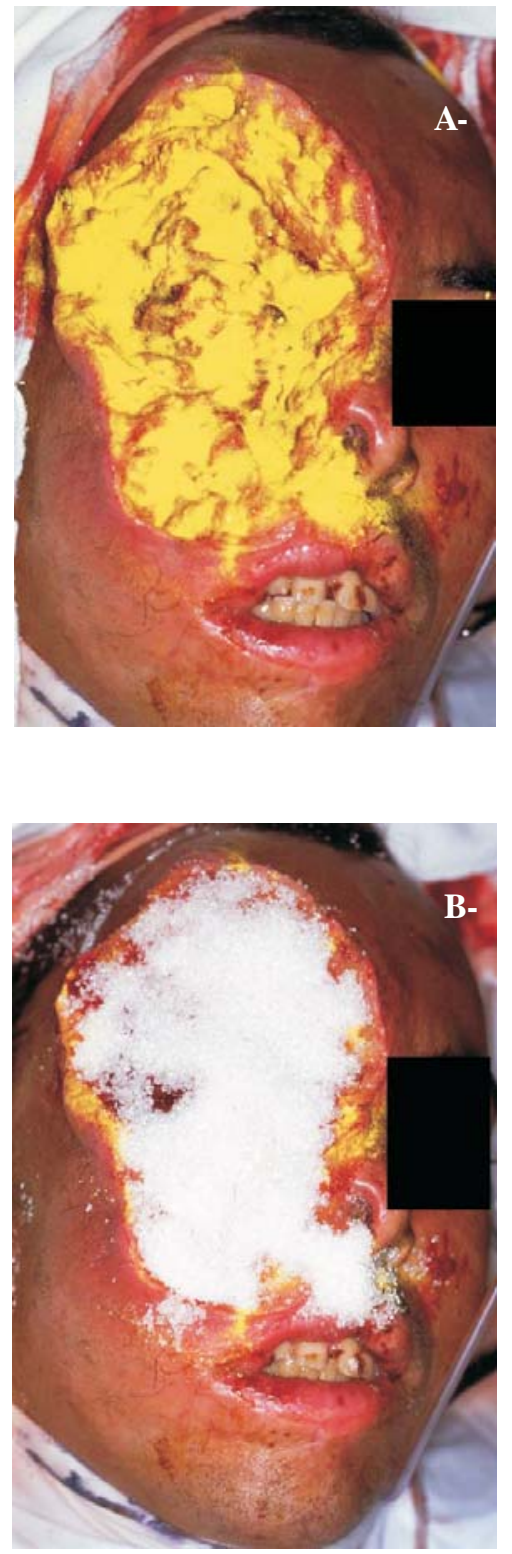

Figura 4 - A- Camada de Iodofórmio antes da colocação do açúcar; B- Açúcar cristalizado sobre a ferida.

O paciente foi devidamente proservado e não houve nenhuma complicação em relação ao andamento do tratamento, bem como se observou a cicatrização total da ferida em 6 meses. Notou-se apenas o comprometimento estético devido à perda de tecido epitelial e conjuntivo ao redor da ferida, sendo que, posteriormente, o paciente foi encaminhado para correção plástica da cicatriz e confecção de prótese bucomaxilo-facial. (figuras 5A e 5B.)
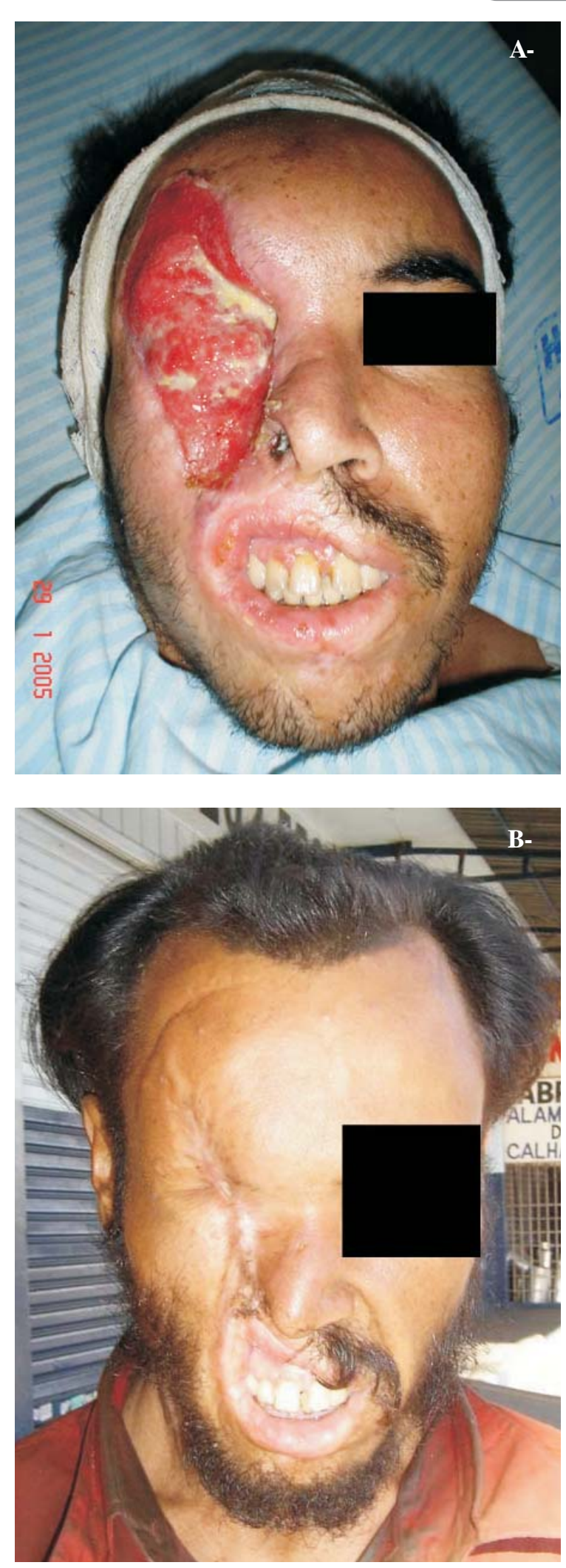

Figura 5 - A- Período de cicatrização da ferida (20 dias); Cicatrização total da ferida (6 meses). Note o comprometimento estético da região. 


\section{Discussão}

Alguns casos de localizações raras de miíase têm sidos descritos comprometendo a cavidade bucal, cavidade nasal e região gengivo-alveolar. Alguns casos de miíase nasal são causados por diversas espécies de dípteros, como por exemplo, a Cochilomyia. A semelhança do agente Lucilia homnivorax de Coquerel (mosca varejeira) também pode provocar enganos no diagnóstico diferencial do agente causador. Para Davis e Shuman (1982), as pessoas que viajam para zonas tropicais podem infestar-se por várias espécies da família Calliphoridae, Phoenicia, Phormia e Lucilia, causando feridas e osteomielites. Quesada, Navarrete e Maeso (1990) descreveram um caso de miíase nasal e detectaram também a presença do Oestrus ovis invadindo, inclusive, os seios maxilares. Denion et al. (2004), num estudo retrospectivo de oftamomiíase externa, afirmaram que a Dermatobia hominis é o agente causador da maioria das miíases humanas. Outros trabalhos como os de Çaça Ihsan et al. (2003), Couppié (2005), Shinohara et al.(2004), Neira, Muñoz e Cantero (2002), citaram também a Cochliomyia homnivorax como as principais causadoras das míiases humanas cavitárias ou cutâneas nas regiões tropicais. Gregory et al.(2004)e Baliga, Davis, Rajasekhar (2001), relatam que a maioria dos casos de miíase orbitária é causada pela família de mosca Oestrus ovis. Não realizamos o estudo de identificação das larvas pelo fato de que, o tratamento, independente da sua espécie, segundo a literatura pesquisada, não difere entre as mesmas. O caso relatado é compatível com os citados na literatura em que estudamos no que se refere aos sinais e sintomas, desconforto e presença de secreção. Segundo Çaça et al. (2003), os distúrbios podem ser benignos e até assintomático, mas dependendo do grau de infestação, podem tornar-se sérios, desagradáveis e até levar à morte.

Quanto ao tratamento, tem-se tentado vários métodos como a remoção mecânica e debridamento e administração medicamentosa para combater infecções secundárias e dor, segundo os autores consultados. Normalmente, deve-se observar o quadro clínico do doente e condições de higiene e, posteriormente, proceder a remoção mecânica das larvas, remoção dos tecidos necróticos e uso de medicamentos tópicos e sistêmicos (COUPPIÉ et al., 2005). O tratamento sistêmico no combate às infecções secundárias e também no cobate às larvas de localização cavitária é atualmente utilizada (COUPPIÉ et al., 2005; DAVIS e SHUMAN, 1982; DENION et al., 2004, EVERRETT, DE VILLEZ, LEWIS, 1977; RIBEIRO et al., 2001) e recomendam o uso de antimicrobianos no combate a infecções secundárias e a ivermectina para extermínio de larvas intracavitárias. Rodriguez et al. (2003), relataram um caso de miíase associada a carcinoma basocelular de órbita, e tratado também com ivermectina previamente ao ato cirúrgico, concluindo que a mesma pode ser utilizada com eficácia no tratamento de mí́ase orbitária. Já Baliga et al.(2001) descrevem o uso de aplicação local de óleo de turpentina nas primeiras 48 horas, éter e clorofórmio e, após, remoção mecânica das larvas. No caso clínico apreseantado, a escolha da associação do açúcar cristalizado (empírico) teve a finalidade de contribuir com a drenagem de secreção seropurulenta, já que o mesmo, com suas características hidrófilas, promovem uma desidratação do meio e também um desequilíbrio osmótico dos microrganismos. Além disso, o açúcar contribui para o desenvolvimento e maturação do tecido de granulação e também formação de fibras colágenas (HADDAD, BRUSCHI, MARTINS, 2000). Para Haddad, Bruschi e Martins (2000), em casos de incisões cirúrgicas infectadas, o açúcar cristal não influenciou no seu processo de cicatrização quando em indivíduos desnutridos, obesos e com idade avançada. Já o iodofórmio possui ação bactericida e antiséptica, sendo auxiliar na reparação tecidual. Salientamos também que não encontramos estudos que utilizaram o açúcar com coadjuvante no tratamento de cicatrização de feridas causadas por miíase.

\section{Conclusões}

- As miíases cutâneas ou cavitárias humanas têm o mesmo agente etiológico, variando em algumas famílias de dípteros e comprometem indivíduos que apresentam um baixo padrão sócio-econômico, em traumatismos com solução de continuidade dos tecidos, que possuem higiene corporal precária associado às 
vezes ao alcoolismo, paciente epiléptico, debilidade senil, seqüelados de AVC isquêmico ou ainda as doenças granulomatosas como a leishmaniose, a hanseníase, bem como aqueles indivíduos em íntimo contato com animais domésticos.

- As formas de tratamento incluem desde a remoção mecânica das larvas, remoção dos tecidos e restos necróticos, recuperação do bom estado geral do paciente, prevenção de infecções secundárias e a profilaxia com a ivermectina oral ou sistêmica.

- O tratamento deve ser escolhido segundo a complexidade de cada caso, levando em consideração a área atingida e às condições locais e gerais de cada paciente.

- Recursos de imagens são essenciais para a localização e delimitação do comprometimento ósseo e de tecidos moles na região da lesão.

\section{REFERÊNCIAS}

1 BALIGA, M.J.; DAVIS, P.; RAJASEKHAR, V. Orbital myiasis: a case report. Int. J. OralMaxillof. Surg., v. 30, p.83-84, 2001

2 ÇAÇA, I.; ÜNLU, K.; ÇAKMAK, S.S.; BILEK, K.; SKALAR, Y.B. ; ÜNLU, G. Orbital miíase: Case Report. Jpn J Ophtalmol, Japão, v. 47, n. 4, p. 412-414, 2003.

3 COUPPIÉ, P.; ROUSSEL, M.; RABARISON, P.; SOCKEEL, J.M.; SAINTE-MARIE, D.; MARTY, C.; CARME, B. Nosocomial nasalmyiasis owing to Cochliomyia hominivorax: a case in French Guiana. International Journal of Dermatology, United States, v. 44, n. 4, p.302-303, 2005.

4 DAVIS, E. e SHUMAN, C. Cutaneous myiasis: devils in the flesh. Hosp Pract (Off Ed). United States, v. 17, n.12, p. 115, 119, 122-3, 1982

5 DENION, E.; DALEM P.H.; COUPPIÉ, P.; AZNAR, C.; SAINTE-MARIE, D.; CARME, B.; PETIBON, J.; PRADINAU.D. R.; GÉRARD, M. External ophathalmomyiasis caused by Dermatobia hominis. A retrospective study of nine cases and a review of the literature. Acta Ophthalmol. Scand., v. 82, n. 5, p. 576-84, Oct., 2004.

6 EVERRETT, D.; De VILLEZ, R.L.; LEWIS, C. W. Cutaneous myiasis due to Dermatobia hominis. Arch Dermatol. v. 113, n.8, p. 1122, 1977.

7 GREGORY, A. et al. Ophthalmomyiasis caused by the sheep bot fly oestrus ovis in Northern Iraq. Optmetry an Vision Science, v. 8, n.8, p.586-90, 2004.

8 GUILLOZET, N. Diagnosing myiasis. JAMA, v. 244, n. 7, p.698-699, 1980 .
9 HADDAD, M. C. L; BRUSCHI, L. C.; MARTINS, E. A. P. Influência do açúcar no processo de cicatrização de incisões cirúrgicas infectadas. Rev. Latinoam. Enfermagem, v.8, n.1, p.57-65, 2000.

10 NEIRA, P.; MUÑOZ, N.; CANTERO, D. Miasis auricular por Cochliomyia hominivorax (Díptera: Calliphoridae) (Coquerel, 1858). Rev.Méd Chile, San Tiago, v.130, n. 8, p.907909, 2002.

11 PRATA, M.B; HADDAD,C.M.; GOLDENBERG, S.; SIMÖES,M.J.; MOURA, A.R.;TRABULSI, L.R. Uso tópico do acúcar em ferida cutânea: estudo experimental em rato. Acta cir.brás, v.3, n. 2, p.43-8, 1988.

12 QUESADA, P.; NAVARRETE, M.L.; MAESO, J. Nasal myiasis due Oestrus ovis larvae. Eur Arch Otorhinolaryngoly, Germany, v. 247, n. 2, p.131-2, 1990.

13 RIBEIRO, F.A.Q.; PEREIRA, C.S.B.; ALVES, A.; MARCON, M.A. Tratamento da mí́ase cavitária com ivermectina oral. Rev. Brás. de Otorrinolaringologia, São Paulo ,v.67, n. 6, p. 755761, 2001.

14 RODRIGUEZ, M.E.L.; AOKI, L.; NICOLETTI, A.G.; MATAYOSHI, S.; FERNANDES, J.B.V.D. Ivermectina no tratamento de miíase orbitária: relato de caso. Arq. Bras Oftalmol, v. 66, n. 4, p.519-21, 2003.

15 SHINOHARA, E.H.; MARTINI, M.Z.; OLIVEIRANETO, H.G.; TAKAHASHI, A. Oral myiasis atreated with ivermectin: case report. Braz. Dent. J., v.15, n.1, p.79-81, 2004. 